"Os desafios para formar hoje o engenheiro do amanhã"

\title{
ANÁLISE DA APLICAÇÃO DE UMA METODOLOGIA ATIVA NA \\ ENGENHARIA DE PRODUÇÃO PARA O ENSINO DE PRODUÇÃO ENXUTA E ELIMINAÇÃO DE DESPERDÍCIOS EM LINHAS PRODUTIVAS
}

Fernanda Broetto Rocha - fernandabroettorocha@gmail.com

Instituto Federal do Espírito Santo - Campus Cariacica

Rodovia governador José Sette, $\mathrm{n}^{\circ} 184$

29150-410 - Cariacica - ES

Gabriela Sales do Espírito Santo - gabrielasales178@gmail.com

Instituto Federal do Espírito Santo - Campus Cariacica

Rodovia governador José Sette, $\mathrm{n}^{\circ} 184$

29150-410 - Cariacica - ES

Cintia Tavares do Carmo - cintiata@ifes.edu.br

Instituto Federal do Espírito Santo - Campus Cariacica

Rodovia governador José Sette, $\mathrm{n}^{\circ} 184$

29150-410 - Cariacica - ES

Daniela da Gama e Silva Volpe Moreira de Moraes - daniela.moraes@ifes.edu.br Instituto Federal do Espírito Santo - Campus Cariacica

Rodovia governador José Sette, $\mathrm{n}^{\mathrm{o}} 184$

29150-410 - Cariacica - ES

Resumo: $O$ trabalho tem como objetivo desenvolver as competências relacionadas a Produção Enxuta por meio da aplicação de um jogo de simulação de linhas de produção de carros Lego, baseado nos 8 desperdícios classificados por Tubino (2015). Trata-se de uma pesquisa empírica, realizada a partir da elaboração de um jogo de simulação de linhas de produção de fábricas no modelo tradicional e enxuto. As simulações realizadas no modelo tradicional evidenciaram os desperdicios na linha produtiva e, assim, foi possivel propor melhorias de modo a eliminar esses desperdícios e implantar um modelo enxuto de produção. A aplicação da aprendizagem ativa com o uso de jogos e simulações no curso de Engenharia de Produção contribuiu para o processo de aprendizagem dos alunos no que diz respeito à análise e identificação de melhorias de um processo produtivo.

Palavras-chave: Aprendizagem Ativa. Engenharia de Produção. Desperdícios. Modelo Tradicional. Modelo Enxuto. 


\section{INTRODUÇÃO}

As técnicas de ensino na Engenharia sofreram relevantes alterações nos últimos anos em função das mudanças ocorridas no mercado de trabalho e habilidades demandadas por ele. Surge, então, a necessidade de vivência prática e pensamento crítico para garantir ótimos resultados educacionais e formar profissionais mais críticos e proativos, o que pode ser alcançado com a utilização da aprendizagem ativa.

A aprendizagem ativa pode ser considerada um conjunto de ações, ou eventos, planejados de forma que os participantes se sintam motivados a processar, aplicar, interagir e compartilhar suas experiências, como parte do processo educacional (INSTRUCTION, 2010). De maneira concisa, pode-se dizer que é qualquer método instrucional que incorpore os estudantes no processo de aprendizagem, o que requer, portanto, que eles executem atividades significativas de aprendizagem e raciocinem sobre o que estão fazendo (PRINCE; FELDER, 2006).

Em geral, os métodos de ensino tradicionais não possuem a eficácia desejada para promover uma mudança de comportamento relevante no alunado, em especial no ensino superior. Além disso, as novas Diretrizes Curriculares Nacionais do Curso de Engenharia explicitam o estímulo ao "uso de metodologias para aprendizagem ativa, como forma de promover uma educação mais centrada no aluno" (BRASIL, 2019).

A aplicação de um jogo para simular uma linha de produção apresenta-se como uma metodologia de aprendizado eficaz na formação das competências do futuro profissional da Engenharia de Produção.

É neste contexto que o presente trabalho se propõe a estruturar e analisar um jogo de simulação de linhas de produção de carros de peças Lego para desenvolver competências relacionadas à Produção Enxuta.

O trabalho é resultado de uma iniciação científica desenvolvida no âmbito do Centro de Excelência em Manufatura (CEM) do Instituto Federal do Espírito Santo, Campus Cariacica; um laboratório específico para o desenvolvimento de atividades de aprendizagem ativa da Engenharia de Produção.

\section{REFERENCIAL TEÓRICO}

Uma ótima forma de aprender é associar com equilíbrio atividades, desafios e informações contextualizadas. Segundo Morán (2015), os alunos devem estar envolvidos na proposta de ensino para que a aprendizagem seja efetiva.

De acordo com Prince e Felder (2006), as pessoas se sentem mais motivadas quando entendem de forma clara a finalidade do que estão estudando.

Prince (2004) conceitua a aprendizagem ativa como um método de instrução que engaja os alunos no processo de aprendizagem. A aprendizagem ativa exige que os alunos ao participarem de atividades reflitam sobre o que fizeram e, assim, tenham uma aprendizagem significativa. Os elementos do núcleo de aprendizagem ativa são atividades em que há o envolvimento do aluno no processo de aprendizagem, muitas vezes contrastada com a palestra tradicional, onde os alunos passivamente recebem informações do instrutor.

Os professores podem adotar diferentes formas de metodologias ativas no intuito dos alunos desenvolverem a capacidade de trabalhar em equipe, resolverem problemas e fazerem análises críticas. Tal fato, torna o aprendizado significativo ao engajar tanto os professores quanto os alunos (SILVA; PESCE; NETTO, 2018).

O jogo é utilizado como um meio pedagógico que conduz e estimula a aprendizagem, de forma que os alunos visualizem de forma lúdica a teoria vista em sala de aula (CHAGURI, 2019). 
A aplicação de jogos e simulações para a compreensão desses conceitos operativos favorecem o aprendizado dos alunos, que passam a distinguir, por exemplo, a diferença entre produção em massa e produção enxuta e constatam, mais facilmente, a presença de desperdícios ao longo do processo de produção (REGIO et.al., 2012).

Segundo Tortorella, Miorando e Fetterman (2018), a utilização de aprendizagem ativa no ensino de produção enxuta, nos cursos de Engenharia de Produção, amplia as dimensões de processamento e percepção de informações do alunado, o que permite preencher lacunas que o modelo de ensino tradicional não é capaz.

Dessa forma, é possível que os alunos identifiquem elementos importantes em um processo produtivo como, por exemplo, desperdícios e tenham um olhar crítico sobre possíveis melhorias.

A produção enxuta, também conhecida como manufatura enxuta, tem origem no Sistema Toyota de Produção e tem foco na eliminação de desperdícios com o objetivo de reduzir custos, aumentar a qualidade e a velocidade na oferta dos produtos aos clientes (WERKEMA, 2011).

Desperdício pode ser definido como qualquer atividade humana que consome recursos, mas que não cria valor (WOMACK; JONES, 2004). De acordo com Tubino (2015), os desperdícios podem ser classificados como: desperdício de superprodução, estoque, transporte, espera, processamento desnecessário, movimentos improdutivos, produtos defeituosos e intelectual.

Por exemplo, produtos acabados, produtos semi-acabados ou peças e suprimentos mantidos no estoque não agregam valor. Pelo contrário, aumentam o custo de operações, ocupando espaço e exigindo mais equipamentos e instalações, como armazéns, empilhadeiras e sistemas de transporte computadorizados (IMAI, 2014).

Segundo Womack e Jones (2004), uma poderosa maneira de eliminar desperdícios é utilizar o pensamento enxuto, seja na manufatura ou nos serviços. Esta maneira de pensar o sistema de produção tem por objetivo alinhar na melhor sequência as ações que criam valor e realizar essas atividades sem interrupções.

$\mathrm{Na}$ manufatura enxuta busca-se constantemente inserir melhorias ao sistema produtivo e, consequentemente, eliminar desperdícios. De acordo com Tubino (2015), a melhoria contínua, ou kaizen em japonês, é o princípio de que nenhum dia deve se passar sem que se melhore sua posição competitiva. Um ponto importante desse princípio é que todos devem ser responsáveis por esse movimento de melhoria e devem trabalhar nesse sentido dentro de sua esfera de atuação. Nota-se que com a prática de melhoria contínua pode-se obter resultados cada vez melhores em relação a eliminação dos desperdícios.

\section{MÉTODO}

Trata-se de uma pesquisa empírica, visto que objetiva gerar conhecimentos para aplicação prática dirigidos à solução de problemas específicos.

O método de aprendizagem desenvolvido no projeto de iniciação científica consiste na aplicação de um jogo de simulação para a compreensão dos conceitos de produção enxuta, baseado nos oito desperdícios citados por Tubino (2015). A dinâmica teve como objetivo simular fábricas no modelo tradicional e no modelo enxuto de produção.

Inicialmente, para o desenvolvimento do jogo, foi feita uma observação in loco da aplicação de um jogo com peças Lego que simulava fábricas de carros na disciplina optativa de "Lean Manufacturing", com o objetivo de identificar os métodos aplicados na aprendizagem por meio de jogos. Após melhorias nessa versão, que foi denominada 00, foi possível realizar as versões seguintes. Para aplicação do jogo, este foi dividido em 3 versões: versão 01 , destinada a realização da simulação de uma fábrica de carros no modelo tradicional 
de produção, versão 02 , referente à simulação de uma fábrica de carros no modelo enxuto de produção e versão 03, destinada à inserção de novos cenários e validação do aprendizado. Devido a pandemia da Covid-19 em 2020 que ocasionou a suspensão das aulas presenciais, não foi possível realizar a última versão do projeto.

A simulação observada (00) foi aplicada em um grupo de alunos que já possuíam o conhecimento sobre o tema. Dessa forma, foi possível analisar as possíveis falhas existentes no jogo que estava em desenvolvimento e realizar as melhorias necessárias para a versão 01 . Posteriormente, a simulação (01) foi realizada em grupos de controle compostos por alunos que não possuíam conhecimento dos conceitos operativos relativos ao tema central do projeto. Este grupo de controle foi observado durante 15 (quinze) simulações, não tendo sido fornecidas instruções prévias sobre os conceitos de produção enxuta aplicados ao jogo. Os dados da simulação foram coletados e armazenados para análise futura.

Em seguida, a aplicação da segunda versão foi realizada em um grupo de controle composto por alunos que já possuíam conhecimento dos conceitos operativos e, portanto, não houve necessidade da realização de treinamento para esse grupo. Nessa versão, foram realizadas 15 (quinze) simulações que permitiram a visualização e aplicação dos conceitos de produção enxuta.

Finalmente, foi realizada uma análise quantitativa com o objetivo de comparar as duas etapas.

\section{DINÂMICA DO JOGO}

Em todas as fases da dinâmica, independentemente do tipo de produção (tradicional ou enxuta) aplicado, foram fabricados dois modelos de carrinhos (A e B) que se diferenciavam apenas na parte da cabine e do motor, mas com a montagem realizada exatamente com as mesmas peças, como pode ser visto na Figura 1. Em cada aplicação realizada do jogo foram feitas 15 simulações.

Figura 1 - Modelos A e B dos carrinhos Lego

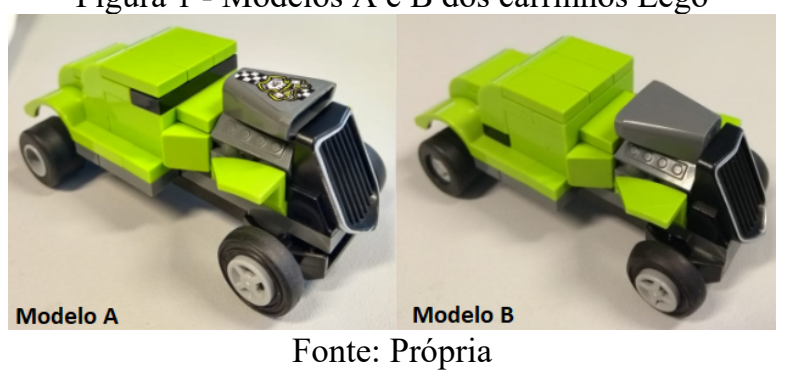

Em cada fábrica, os carros eram produzidos divididos em quatro blocos, nomeados como: chassi; porta-malas/assoalho; cabine e motor, os quais foram alocados a frente do respectivo posto de trabalho responsável. A equipe de produção foi formada por montadores (responsáveis por montar os carrinhos), fiscais (responsáveis por contabilizar peças que caíssem no chão, peças movimentadas por pessoas não autorizadas, pessoas que corressem ou esbarrassem durante o transporte e contabilizar o estoque final no processo), supervisores (responsáveis por retirar o pedido e comunicar a equipe sobre o modelo a ser produzido) e abastecedores (responsáveis por abastecer cada posto de trabalho, transportar componentes de um departamento para outro e fazer a entrega do produto final ao cliente).

Vale ressaltar que para o modelo de produção enxuta, a função de transportar os componentes do carrinho de um posto de trabalho para outro passou a ser designada aos montadores ao invés dos abastecedores. 
"Os desafios para formar hoje o engenheiro do amanhã"

A cada 2 minutos, um pedido deveria ser retirado e um carrinho deveria ser entregue ao cliente, com tolerância de 30 segundos que era contabilizada como atraso. E ao final do ciclo de 15 simulações da dinâmica foram contabilizados os problemas enumerados pelo fiscal e os pedidos entregues com atraso, com problemas de qualidade ou não entregues, o que foi classificado como desperdício.

\subsection{Descrição da versão 00}

Conforme mencionado anteriormente, essa etapa da pesquisa foi composta por uma observação in loco da aplicação do jogo com peças da Lego que simulava fábricas de carros, efetuada na disciplina optativa de "Lean Manufacturing".

A proposta do docente que ministrou a disciplina era desenvolver uma prática lúdica capaz de propiciar o aprendizado dos conceitos operativos da fábrica no modelo tradicional e da fábrica no modelo enxuto. Com isso, a dinâmica observada foi composta por duas fases, modelo tradicional de produção e modelo enxuto de produção. O sistema era constituído por 4 sub-fábricas, cada uma com 4 montadores, 1 fiscal, 1 supervisor e 1 abastecedor.

A fábrica no sistema tradicional de produção era composta por 4 departamentos, cada um responsável por produzir um componente do carrinho e, em conjunto, 1 carrinho. $\mathrm{O}$ estoque no modelo tradicional não possuía uma organização lógica, mas os abastecedores recebiam uma lista com a quantidade de peças que deveriam ser entregues a cada montador. Já na fase do sistema de produção no modelo enxuto, o estoque foi modificado de modo a seguir uma organização lógica que facilitasse a distribuição das peças pelo repositor, para diminuir os desperdícios no processo. Cada sub-fábrica foi formulada em layout celular formado por 4 postos de trabalho em linha, sendo que em uma célula foi possível montar um carrinho completo.

\subsection{Descrição da versão 01 (Fábrica Tradicional)}

A dinâmica foi realizada com alunos do segundo período do curso de Engenharia de Produção que possuíam conhecimento em "Introdução a Engenharia de Produção", mas nenhum conhecimento, a não ser o empírico, sobre manufatura enxuta. Sendo assim, foi realizada uma simulação com carrinhos da Lego, a partir do modelo tradicional de produção.

A fábrica foi dividida em layout departamental formado por 4 departamentos (Figura 2), sendo que em cada um desses era produzido um dos componentes do carro. Durante a realização desta simulação/dinâmica houve a participação de um grupo de controle formado por 7 pessoas: 4 montadores, 1 abastecedor, 1 fiscal e 1 supervisor. 


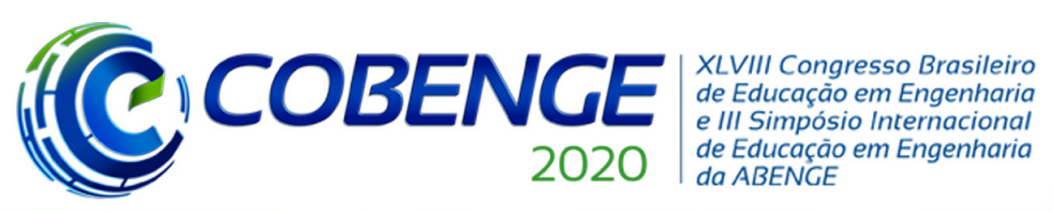

"Os desafios para formar hoje o engenheiro do amanhã"

Figura 2 - Layout da fábrica e composição das mesas durante as simulações no modelo tradicional
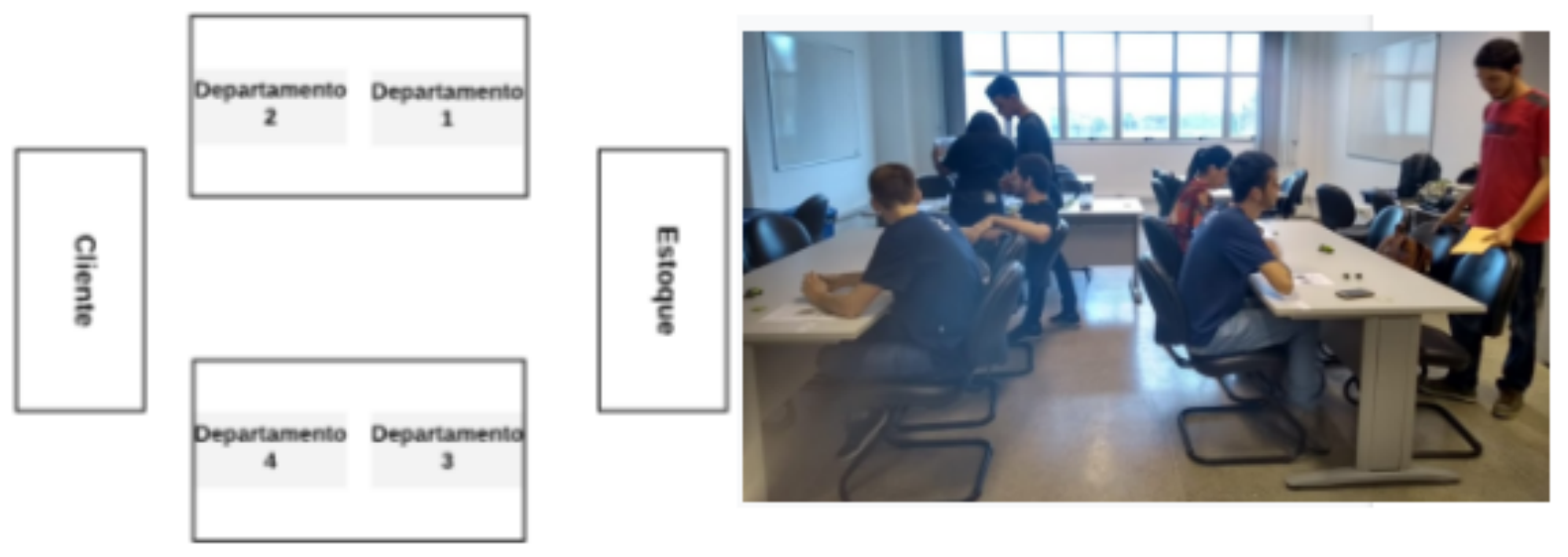

Fonte: Própria

Nessa fábrica tradicional, o estoque não teve nenhuma organização lógica que facilitasse a distribuição das peças pelo repositor, apenas foram colocados potes com o nome e o número de identificação das peças, que não poderiam ser alterados no decorrer da execução da dinâmica. O repositor apenas recebeu uma lista, dividida por departamentos, da quantidade de cada peça que deveria ser entregue nos departamentos. Vale ressaltar que peças uma vez entregues no posto de trabalho não poderiam ser retiradas até a contabilização ao final da dinâmica.

\subsection{Descrição da versão 02 (Fábrica Enxuta)}

A dinâmica foi realizada com alunos do sexto período do curso de Engenharia de Produção que possuíam conhecimento nas disciplinas de "Introdução à Engenharia de Produção" e "Sistemas de Produção" e, consequentemente, conceitos operativos de manufatura enxuta. Assim, para esse grupo de controle, não foi necessário realizar o treinamento sobre a classificação dos 8 desperdícios (TUBINO, 2015).

A fábrica foi formulada em layout celular formado por 4 postos de trabalho em linha (Figura 3), sendo que em uma célula foi possível montar um carro completo por simulação. $\mathrm{O}$ grupo de controle foi composto por 6 pessoas: 4 montadores, 1 repositor e 1 supervisor.

Figura 3 - Layout da fábrica e composição das mesas durante as simulações no modelo enxuto
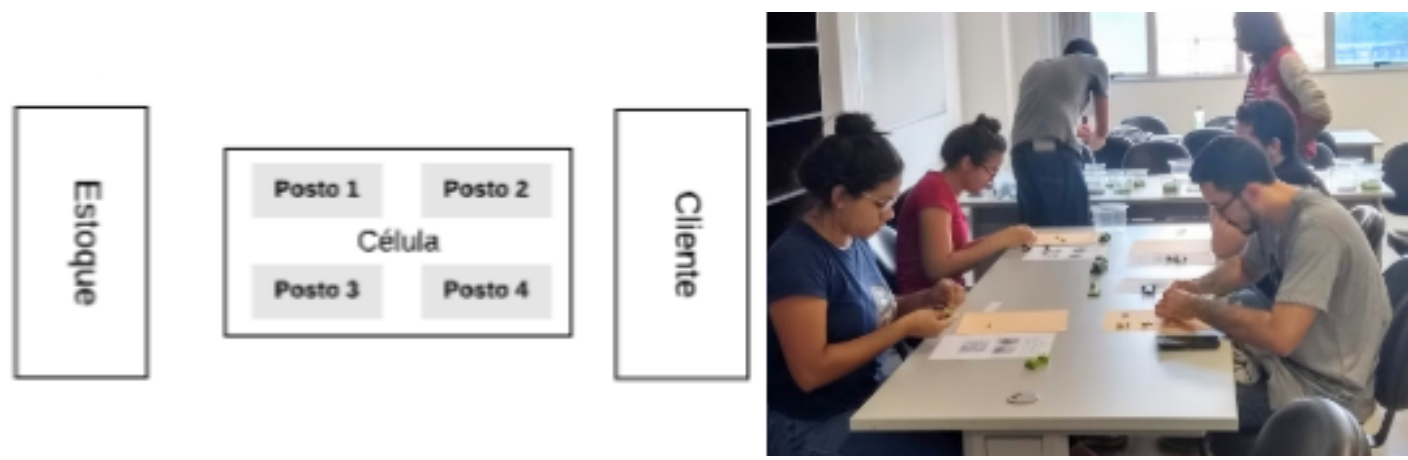

Fonte: Própria

Em cada posto de trabalho foi posicionado um papel delimitando a área de trabalho, o que facilitou também para que o repositor visualizasse o posto de trabalho que necessitava de matéria-prima. Nessa fábrica enxuta, o estoque tinha uma organização lógica em que as peças foram divididas por bloco e localizadas de acordo com a quantidade necessária para a 
"Os desafios para formar hoje o engenheiro do amanhã"

montagem. Essa mudança atribuiu rapidez a atividade de distribuição e, assim, contribuiu para a diminuição dos desperdícios do processo.

\section{RESULTADOS E DISCUSSÃO}

A partir da análise quantitativa, foi possível verificar que no modelo tradicional, dos 15 pedidos feitos, apenas $20 \%$ foram entregues dentro das especificações, sendo $13,33 \%$ com atraso, $13,33 \%$ com problemas de qualidade e 53,33\% não foram entregues.

Dessa forma, foram contabilizados os desperdícios de produtos defeituosos (carrinhos com problema de qualidade), movimentos improdutivos (pegar peças que caíram no chão), transporte (deslocamento do transportador da atividade de reposição de peças para transporte de componentes de um departamento para outro), estoque (peças entregues no posto de trabalho e não utilizadas) e espera (componentes que ficaram muito tempo sem ser processados por falta de peças necessárias para a montagem).

A partir dos desperdícios encontrados no modelo tradicional foram determinadas as mudanças que seriam realizadas e executadas no modelo enxuto de forma a diminuir/eliminar esses desperdícios. As mudanças foram aplicadas para o modelo enxuto, resultando na entrega de todos os pedidos. Em um total de 15 pedidos, foram entregues 14 carrinhos dentro das especificações e apenas 1 pedido foi entregue com atraso. Além disso, durante a simulação não foram observados desperdícios no processo produtivo.

\section{CONSIDERAÇÕES FINAIS}

O desenvolvimento deste trabalho permitiu aos alunos ingressantes no curso de Engenharia de Produção do Instituto Federal do Espírito Santo, Campus Cariacica, a vivência com um modelo tradicional de produção e, ainda, oportunizou aos mesmos a visualização de forma empírica das possíveis melhorias para aumentar a eficiência do processo produtivo.

A aprendizagem ativa, com a utilização de jogos e simulações que vão além do escopo da aprendizagem cognitiva, contribuiu para a disseminação da mudança de visão relativa dos docentes como centro do processo de ensino-aprendizagem (aulas expositivas) para a visão centrada nos alunos (simulações e jogos).

Na simulação da fábrica do modelo enxuto, com alunos que já possuíam o conhecimento teórico a respeito de produção enxuta e desperdícios produtivos, foi possível notar as alterações relevantes no processo produtivo após a eliminação dos desperdícios. Isso permitiu aos alunos "aprender fazendo", algo que é essencial a carreira de um profissional da Engenharia de Produção.

Durante as simulações foi possível observar o alunado com uma visão crítica, engajados com a visualização das possibilidades de melhorias do processo produtivo, demonstrando que o objetivo principal de desenvolver competências da Produção Enxuta nos participantes do jogo foi cumprido.

\section{REFERÊNCIAS}

BRASIL. Conselho Nacional de Educação. Resolução CNE/CES nº 2, de 24 de abril de 2019. Diretrizes Curriculares Nacionais do Curso de Graduação em Engenharia. Diário Oficial da República Federativa do Brasil. Brasília, DF, Seção I, p. 43, 24 abr. 2019. Disponível em: $<$ http://www.in.gov.br/web/dou/-/resolu\%C3\%87\%C3\%83o-n\%C2\%BA-2-de-24-de-abril-de2019-85344528>. Acesso em: 23 set. $/ 2019$. 
"Os desafios para formar hoje o engenheiro do amanhã"

CHAGURI, Jhonathas de Paula. O uso de atividades lúdicas no processo de ensino/aprendizagem. Disponível

em: $<$ http://www.unicamp.br/iel/site/alunos/publicacoes/textos/u00004.htm $>$ Acesso em:05 de abr. 2019

IMAI, Masaaki. Gemba Kaizen: Uma abordagem de bom senso à estratégia de melhoria contínua. Porto Alegre: Bookman,2014.

INSTRUCTION. A Guide to Teaching and Learning Practices. Center for Teaching \& Learning, 6th edition, Florida State University, 2010.

PRINCE, M. J. Does Active Learning Work? A Review of the Research. Journal of Engineering Education, v. 93, n. 3, p. 223-231,2004. Disponível em:<

https://onlinelibrary.wiley.com/doi/abs/10.1002/j.2168-9830.2004.tb00809.x> Acesso em: 20 de nov. 2018.

PRINCE, M. J.; FELDER, R. M. Inductive Teaching and Learning Methods: Definitions, Comparisons, and Research Bases. Journal of Engineering Education, 2006.

REGIO, R. L. S. et.al. Fatores contextuais críticos para o sucesso da aplicação de atividades lúdicas na elevação dos conhecimentos sobre produção enxuta: um estudo de caso. In: XXXII Encontro Nacional de Engenharia e produção, 2012, Bento Gonçalves.

SILVA, M. I. O.; PESCE, L.; NETTO, A. V. Aplicação de sala de aula invertida para o aprendizado de língua portuguesa no ensino médio de escola pública. Vol. 5 , n. 1, Dezembro/2018. <Disponível em:

https://www.nied.unicamp.br/revista/index.php/tsc/article/view/190> Acesso em : 10 de Out. de 2019.

TORTORELLA, G.L.; MIORANDO, R. F.; FETTERMANN, D.C.. A relação entre métodos de ensino e estilos de aprendizagem lean manufacturing: uma pesquisa empírica sobre um curso de pós-graduação em engenharia de produção. Revista Produção Online.

Florianópolis, SC, v. 18, n. 1, p. 93-117, 2018. Disponível

em: $<$ https://www.producaoonline.org.br/rpo/article/view/2682/1626>.Acesso em: 1 de Abr. de 2020 .

TUBINO, Dalvio Ferrari. Manufatura Enxuta como Estratégia de Produção: A chave para a produtividade industrial. São Paulo: Atlas, 2015.

WERKEMA, Cristina. Lean seis sigma: introdução às ferramentas do Lean Manufacturing. ed. 2. Rio de Janeiro: Elsevier, 2011.

WOMACK, James P.; JONES, Daniel T.. A mentalidade enxuta nas empresas: elimine o desperdício e crie riqueza. Rio de Janeiro: Elsevier, 2004 - 15ª Reimpressão. 
"Os desafios para formar hoje o engenheiro do amanhã"

\title{
ANALYSIS OF THE APPLICATION OF AN ACTIVE METHODOLOGY IN PRODUCTION ENGINEERING FOR TEACHING LEAN PRODUCTION AND ELIMINATION OF WASTE IN PRODUCTION LINES
}

\begin{abstract}
The work aims to develop skills related to Lean Production through the application of a Lego car production line simulation game, based on the 8 wastes classified by Tubino (2015). An empirical research was conducted from the elaboration of a simulation game of production factory lines in traditional and lean model. The simulations carried out in the traditional model showed the waste in the production line and, thus, it was possible to propose improvements to eliminate waste and implement a lean production model. The application of active learning with the use of games and simulations in the Production Engineering contributed to the students' learning process regarding the analysis and identification of improvements in a production process.
\end{abstract}

Keywords: Active learning. Production engineering. Waste. Traditional Model. Lean model. 